\title{
NUEVOS DATOS SOBRE EL YACIMIENTO PALEOLIITICO DE LAS DELICIAS: UN TALLER SOLUTRENSE EN EL VALLE DEL MANZANARES (MADRID, ESPAÑA)
}

\author{
New data on the Palaeolithic site of Las Delicias: a Solutrean \\ workshop in the Manzanares valley (Madrid, Spain)
}

\author{
Manuel Alcaraz-Castaño ${ }^{1}$, Mario López-Recio ${ }^{2}$, Marta Roca ${ }^{2}$, Fernando Tapias ${ }^{3}$, \\ Inmaculada Rus ${ }^{4}$, Javier Baena ${ }^{2}$, Jorge Morín ${ }^{3}$, Alfredo Pérez-González ${ }^{5}$ \\ y Manuel Santonja ${ }^{5}$
}

Recibido el 1 de marzo de 2013. Aceptado el 12 de junio de 2013

Resumen. El yacimiento de Las Delicias (Madrid, España), conocido desde la excavación practicada en el sitio por H. Obermaier y P. Wernert a finales de 1917, ha sido desde entonces uno de los referentes clásicos del Paleolitico del valle del Manzanares, a pesar de las variadas interpretaciones que ha originado su problemática colección industrial. Tras un análisis historiográfico de sus interpretaciones, presentamos aquí un primer avance de los resultados obtenidos en un proyecto de investigación sobre este yacimiento, iniciado en el invierno de 2008. Este proyecto, planteado a partir de la excavación de parte de los depósitos cuaternarios aún conservados en Las Delicias, se ha centrado en mejorar nuestro conocimiento geoarqueológico del yacimiento con el objetivo de resolver los interrogantes tradicionales que éste ha propuesto a la disciplina. El análisis tecnológico de la industria lítica recuperada, junto con el estudio litológico y geomorfológico del depósito, permite situar en el Solutrense el yacimiento de Las Delicias. Éste se convierte así en el único emplazamiento conocido en el entorno del Manzanares - hallazgos aislados aparte- con industrias solutrenses en posición estratigráfica bien definida y excavado con metodología actual. Se apunta una primera discusión sobre las implicaciones de los resultados obtenidos en el debate sobre la ocupación humana de la Meseta durante el tramo central del Paleolítico superior.

Palabras clave: historiografía, meseta, Península lbérica, Paleolítico superior, Pleniglacial superior, área de talla, tecnología lítica, reducción bifacial solutrense.

Abstract. The archaeological site of Las Delicias (Madrid, Spain) is known since the excavation conducted at the location by H. Obermaier and P. Wernert in the late 1917. It has been one of the classical references for the Palaeolithic of the Madrid region, despite the varied interpretations that have been posited to explain its problematic lithic assemblage. Following a historiographical analysis of the site's interpretations, we present the results of a research project initiated in the winter of 2008. This project was centered in the excavation of part of the quaternary deposits still present in the area, and its main objective was to gain a better geoarchaeological understanding of the site in order to solve the questions that it has traditionally posed to the discipline. The technological analysis of the lithics, together with the lithological and geomor-

(') Área de Prehistoria, Facultad de Filosofía y Letras, Universidad de Alcalá. C/ Colegios 2. 28801 Alcalá de Henares (Madrid).manuel.alcaraz@uah.es

(2) Departamento de Prehistoria y Arqueología, Universidad Autónoma de Madrid.

(3) Departamento de Arqueología, Paleontología y Recursos Culturales. Auditores de Energía y Medio Ambiente, S.A.

(4) Dirección General de Patrimonio Histórico, Comunidad de Madrid.

(5) Centro Nacional de Investigación sobre Evolución Humana (CENIEH). Paseo Sierra de Atapuerca s/n. 09002 Burgos. manuel.santonja@cenieh.es 
phological analysis of the deposit, allows us to place Las Delicias in the Solutrean period. Thus, besides some isolated finds, this site becomes the only one in the Manzanares area containing Solutrean industries in a well-defined stratigraphic position and excavated with modern methods. We make some reflections on the implications of our findings for the discussion on the human settlement of Central lberia during the middle part of the Upper Palaeolithic.

Keywords: historiography, spanish plateau, Inner Iberia, Upper Palaeolithic, Upper Pleniglacial, lithic workshop, lithic technology, solutrean bifacial reduction.

\section{LAS DELICIAS: HISTORIA DE UN PROBLEMÁTICO YACIMIENTO REFERENTE}

\subsection{Descubrimiento y primera excavación de Las Delicias}

El yacimiento paleolítico de Las Delicias, situado en el valle del río Manzanares (Madrid, España), fue dado a conocer a finales de 1917 por Hugo Obermaier y Paul Wernert. Alertados por el ingeniero de ferrocarriles Alejandro García Guinea, quien descubrió el sitio como consecuencia de las obras para la construcción de un almacén cerca de la estación de tren de Las Delicias -entonces a las afueras de Madrid y hoy en pleno casco urbano (Fig. 1)-, los dos prehistoriadores aún pudieron recuperar buena parte de las piezas de industria lítica aparecida en la trinchera de 14,60 $\mathrm{m}$ de largo realizada por García Guinea, así como emprender una excavación metódica en el lugar. Ésta, adyacente a la anterior, y que comprendió alrededor de $25 \mathrm{~m}^{2}$ (Fig. 2), puso al descubierto varios niveles arqueológicos con industria lítica en un entorno geomorfológico dominado por la deposición de sedimentos finos al aire libre. Se identificó así un yacimiento paleolítico que enseguida se consideraría de gran relevancia, tanto por la notable concentración de industria tallada en sílex que albergaba, como por ser el primer emplazamiento de este tipo localizado en la margen izquierda del río Manzanares (Obermaier y Wernert 1918: 7-11). La importancia científica de este yacimiento, así como su dilatada y problemática trayectoria en el contexto del $\mathrm{Pa}-$ leolítico español hasta la actualidad, fue ya hace unos años resaltada por Santonja et al. (2000).

En la totalidad de superficie excavada, que ascendió a unos $72 \mathrm{~m}^{2}$, Obermaier y Wernert (1918) definieron la siguiente estratigrafía (Fig. 3):

a) Tierra vegetal mezclada con arcilla. 1,20 m de espesor máximo.

b) Arcilla mezclada con pequeñas concreciones caolínicas de color blancuzco. 1,50 m de espesor máximo.

c) Capa arenosa con concreciones arcillosas. Entre 5 y $8 \mathrm{~cm}$ de espesor. Solo apareció en el sector ocupado por el edificio, no en la excavación suplementaria.

d) Arcilla terciaria.
Los excavadores situaron la mayor concentración de industria lítica en la base de la capa $b$, en una potencia de $10-15 \mathrm{~cm}$ (26 cm como máximo), y cuya densidad les llevó a afirmar que, en algunos de sus puntos, el "suelo" estaba a veces como "empedrado". También señalaron la existencia reducida y dispersa de sílex tallados tanto en la parte superior de la capa $b$, como incluso en la base del nivel vegetal (a). Indicaron asimismo que en la zona donde la estrecha capa arenosa (c) se interponía entre la b y la arcilla terciaria (d), la concentración de industria era igualmente patente. No localizaron ningún tipo de vestigio paleontológico (Obermaier y Wernert 1918: 11-14).

\subsection{La primera interpretación de Obermaier y Wernert}

Obermaier y Wernert (1918: 14-16) se ocupan someramente de "los vestigios paleolíticos desperdigados encima" del denso nivel localizado en la base de la capa b. Sobre ellos, que caracterizan como "amorfos" y "atípicos", únicamente se señala su posible caracterización como Musteriense antiguo o quizá, en el caso de los localizados en la base de la capa a, "a lo sumo como una industria de transición al paleolítico superior". Mantienen además que el carácter disperso de los hallazgos indicaría que la funcionalidad del sitio no ha de relacionarse con la vivienda, si no con "hordas primitivas que pasaron de vez en cuando por aquí", o bien con los restos dispersos de un emplazamiento cercano.

En cuanto a lo que denominan "el verdadero yacimiento", en la base de la capa b y del que enseguida resaltan su "evidente carácter achelense", descartan también su caracterización como campamento o sitio de hábitat. Para ello se basan en que "faltan en absoluto huesos de animales o estratos de cenizas o carbones". Así, interpretan este nivel como los restos de un taller, para lo que se basan en la existencia de "enormes cantidades de materia prima [...] almacenadas para el trabajo, en bloques de gran tamaño", en la existencia de "infinidad de desechos atípicos de todas formas y tamaños" producto de la talla, en la escasez de "tipos completamente terminados", y en que la mayoría de piezas aparecen rotas e incompletas. Llamaron también la atención sobre el más que probable origen antrópico de la importante acumulación de sílex, para lo que se basaron en que los afloramientos conocidos más cercanos se encontra- 




\ Figura 1. Localización geográfica del yacimiento solutrense de Las Delicias dentro de la Comunidad de Madrid y del propio municipio de Madrid.

ban en Cerro Negro y los relieves inmediatos a Vallecas y Vicálvaro (Obermaier y Wernert 1918: 16-17).

El estudio de la industria lítica de Las Delicias se realizó bajo los parámetros teórico-metodológicos heredados del programa de investigación - o paradigma, si se prefiere- transformista o evolucionista unilineal. Según este, que la descripción morfotipológica de las piezas líticas constituia la heurística de trabajo fundamental, y los objetivos de la investigación se centraban en la asignación de los conjuntos industriales a épocas concretas a partir de fósiles directores (Vega 2001; AlcarazCastaño 2014). En consecuencia, la muestra estudiada se limitó a una selección de las piezas que a priori parecian presentar una mayor información tipológica. A partir de dicha selección, Obermaier y Wernert presentaron el estudio según grupos tipológicos, que en buena medida también se ordenaban por tamaños:

- En primer lugar destacan los "tipos de tamaño grande", entre los que señalan núcleos toscos y 




ム Figura 2. Planta del almacén donde García Guinea localizó el yacimiento de Las Delicias y excavación suplementaria realizada por Obermaier y Wernert (modificada de Santonja et al. 2000: fig. 2, a partir de Obermaier y Wernert 1918: fig. 3).



\ Figura 3. Estratigrafía de Las Delicias según Obermaier y Wernert (modificado de Santonja et al 2000: fig. 3). El corte superior representa la línea $\mathrm{AB}$ de nuestra figura 1 y el inferior la línea $C D$. Leyenda: (a) tierra vegetal con arcilla; (b) arcilla con concreciones caolínicas blancuzcas; (c) capa arenosa; (d) arcilla terciaria; (x) nivel con concentración de sílex tallados. 
pesados, algunos "amorfos completamente, otros más o menos discoideos y algunos de forma amigdaloide", que en algunos casos originaron hachas de mano "de aspecto del chelense más primitivo" y de bordes toscos y sinuosos (Obermaier y Wernert 1918: 18). Incluyen también aquí grandes raspadores "con retoques lamelares relativamente finos que recuerdan núcleos del paleolítico superior", pero que consideran "pseudo-formas debidas a la casualidad", por lo que no son tenidas en cuenta para la caracterización tipológica del conjunto.

- Relacionadas con el anterior grupo, aunque referidas ya como "tipos clásicos" de la "familia" de las hachas de mano, Obermaier y Wernert (1918:1923) destacan la notable presencia de otras piezas talladas por las dos caras, y a las que se refieren como "la etapa álgida de estos utensilios, siendo en su evolución la forma más perfeccionada". Resaltan, especialmente en el caso de una "punta de hacha de mano", que la cuidadosa talla de estas piezas es "parecida a la técnica de las puntas-hojas de laurel del solutrense" (Fig. 4). Asimismo, interpretan que algunas otras piezas, más gruesas y toscas, y generalmente fracturadas, serían esbozos destinados a la producción de estas puntas, que no fueron llevados a término a causa de su fractura (Obermaier y Wernert 1918: 22). Sin embargo, insisten en la existencia de "verdaderas hachas de mano" de gran tamaño, de bordes cortantes y sinuosos, y que interpretan como instrumentos terminados en su configuración, lo que apoyan además en la identificación de huellas de uso en sus filos (Obermaier y Wernert 1918: Fig. 4).
- Distinguen, por otro lado, "un cierto número de tipos grandes, tallados por una cara", entre los que mencionan una raedera pesada y gruesa con abundante retoque, un "disco tosco" y varias hojas grandes e irregulares (Obermaier y Wernert 1918: 23).

- Reclaman una particular atención para "los tipos de estilo Levallois", de los que dicen que se encuentran en número relativamente grande, si bien en ningún caso en forma de "piezas verdaderamente finas y bien talladas". Señalan así que "puntas clásicas apenas sí existen", limitándose el repertorio a "bastantes lascas planas de formas más o menos ovaladas". Entre ellas destacan una lasca-raspador (Obermaier y Wernert 1918: 23).

- Por último, tras una somera mención a los pobres y ecasos "utensilios pequeños", los autores resaltan la numerosa presencia de lascas "en forma de hojas", de las que dicen que son "el resultado automático de la talla de la piedra", y por tanto no procedentes de tecnologías especificamente laminares. Reproducen cuatro de estas hojas, de las que señalan un "carácter primitivo" que les alejaría de las hojas del Paleolítico superior (Obermaier y Wernert 1918: 25-27).

Tras este análisis, los excavadores atribuyen el conjunto industrial al Paleolítico inferior -que entonces también englobaba las industrias que hoy se incluyen en el medio-, para lo cual se basan en tres evidencias fundamentales (Obermaier y Wernert 1918: 31-33):

1. Ausencia total de "tipos del Paleolítico superior", y especialmente de "las hojas estrechas prismáticas", las cuales entienden que, de tratarse de una in-



৯ FiguRA 4. Dos representaciones gráficas de la misma pieza de Las Delicias, interpretada sucesivamente como "punta de hacha de mano" (Obermaier y Wernert 1918: fig. 8, "punta tenuifoliada esbaikiense" (Obermaier 1925: fig. 92), y foliácea solutrense en fase avanzada de adelgazamiento (Baena y Carrión 2002: fig. 4.36). A: Dibujo de Francisco Benítez (1918). B: Dibujo de Elena Carrión (2002). 
dustria superopaleolítica, "tendrían que encontrarse en grandes cantidades y con todas sus variantes, precisamente en un taller".

2. Presencia significativa de piezas bifaciales, que van desde las más toscas hachas de mano -acompañadas por desechos asociados, también de gran tamaño-, hasta los tipos más finos y delgados, que representan "el punto culminante de las industrias de hachas de mano". Son de hecho estos últimos los que utilizan para proponer una asignación industrial más específica del conjunto, "dentro del marco cronológico de la tipología", al "Achelense final clásico". Aunque reconocen que algunos de estos tipos bifaciales finos recuerdan "por su perfección y talla cuidadosa las formas solutrenses", descartan una atribución industrial a dicho tecnocomplejo, pues indican que en otros yacimientos del Achelense superior, en el Suroeste francés y en Centroeuropa, se encuentran también estos tipos, que consideran "pseudo-solutrenses".

3. Presencia de lascas "de tipo levallois", que los investigadores asumen indicativa de una industria achelense, pues aducen que es en el Achelense superior cuando esta tecnología llega "a su máxima perfección".

Aunque los tres puntos son explicables a partir de la simple lectura empírica realizada por Obermaier y Wernert, resulta necesario contextualizar la interpretación de éstos en el marco epistemológico en el que fue propuesta. Dicho marco determinaba qué preguntas se consideraban relevantes por la disciplina, qué datos debian analizarse para responderlas, y qué metodologías debian seguirse en su estudio (Alcaraz-Castaño 2014). En efecto, el programa transformista, cuya metodología de trabajo, estrictamente empirista-inductivista, provenía de las Ciencias Naturales, y fundamentalmente de la Paleontología, concebía el desarrollo temporal paleolítico como una sucesión compartimentada de pisos geológicos, caracterizados por fósiles directores industriales definidos a través de criterios exclusivamente morfotipológicos. Así, a pesar de las características atípicas que presentaba el conjunto de Las Delicias, su atribución industrial debía atenerse necesariamente a lo estipulado para cada piso geológico: si presentaba bifaces y tecnología levallois, debía pertenecer al Paleolítico inferior, pues ambos elementos eran considerados impropios de cronologías más recientes. En el mismo sentido, a pesar de que los propios investigadores identifican numerosos esbozos y piezas bifaciales en proceso de elaboración, la importancia esencial que presentaba la sistemática tipológica para el programa transformista les conduce a valorar las hachas de mano que consideran acabadas y típicas, y por tanto tipológicamente informativas, como los elementos funda- mentales para establecer la atribución crono-cultural del conjunto. Asimismo, la presencia de láminas y técnicas de talla "que recuerdan" al Solutrense son objeto de una explicación ad hoc, según la cual se aducía el carácter atípico de estos elementos, tanto en número como en morfología, para acomodar a la interpretación propuesta su presencia en un conjunto achelense. Obermaier y Wernert no concebian que un taller del Paleolítico superior pudiera presentar tan pocos elementos laminares, por lo que éstos fueron poco valorados como elementos significativos, cuando no directamente obviados. Esto último fue explícitamente indicado en el caso de "grandes raspadores y piezas esbozadas, con retoques lamelares relativamente finos que recuerdan núcleos del paleolítico superior", lo que determinó que dichas piezas no fueran ni conservadas ni reproducidas en la publicación, por ser consideradas "pseudo-formas debidas a la casualidad" (Obermaier y Wernert 1918: 18). Desgraciadamente, esta circunstancia probablemente nos ha privado de una buena parte de la información recuperada en la primera excavación de Las Delicias.

\subsection{Sucesivas interpretaciones de Las Delicias hasta el siglo XXI}

La importancia que desde el primer momento se le reconoció al yacimiento de Las Delicias, unida a la problemática atribución crono-cultural de su conjunto industrial y la compleja caracterización de la secuencia paleolítica del valle del Manzanares (Santonja et al. 2000, 2011), supusieron que la interpretación ofrecida por Obermaier y Wernert fuera enseguida revisada por la disciplina.

La primera interpretación alternativa fue de hecho propuesta a mediados de los años 20 del siglo pasado por el propio Obermaier. Ésta ha de ser enmarcada en un momento en el que los hallazgos de industrias paleolíticas proliferaban en el valle del Manzanares, y su contextualización geológica se realizaba a partir de la interpretación climática y cronológica de los depósitos derivada del modelo de construcción del valle propuesto por Pérez de Barradas (1923). Por otro lado, la interpretación histórica de la secuencia paleolítica vendría ahora a ser deudora del programa de investigación históricocultural, desarrollado en su aplicación al Paleolítico por los franceses H. Breuil y D. Peyrony, y que se asentaba entonces en la investigación española (Vega 2001; Alcaraz-Castaño 2014). Así, los numerosos niveles achelenses y musterienses que se sucedian en la compleja secuencia que venía destapándose en el valle madrileño, aunque aún eran definidos a través de la sistemática tipológica evolucionista, se hicieron corresponder, según la heurística histórico-cultural, con etnias o grupos humanos definidos. Se configuró así una compleja explicación que aducía los movimientos de grupos humanos desde Centroeuropa y el norte de África, y su pugna con los grupos autóctonos achelenses, como la causa 
de la variación instrumental documentada en las estratigrafías del Manzanares. En este contexto, Obermaier y Pérez de Barradas (1924) en su sintesis del Musteriense madrileño, y el propio Obermaier (1925) en El Hombre Fósil, plantearon una interpretación para Las Delicias en consonancia con los nuevos datos empíricos y, sobre todo, los nuevos marcos metateóricos. Es así como los elementos industriales que habian servido para asignar el lote industrial del yacimiento al Achelense superior, pasaron de considerarse hachas de mano -ya fueran toscas o estilizadas- a relacionarse con las puntas tenuifoliadas esbaikienses del norte africano (Obermaier y Pérez de Barradas 1924: 162-164). En palabras de Obermaier (1925: 206-207), "según los últimos resultados debe considerarse esta industria como Musteriense inferior de tradición acheulense, y Sbaikiense". Unas páginas más adelante la relacionaba con el "Musteriense ibero-mauritánico" (Obermaier 1925: 226-227).

En el terreno puramente empírico, la nueva atribución de Las Delicias y su inserción en la compleja secuencia musteriense madrileña, dominada ahora por las influencias africanas, seguía generando importantes incertidumbres. Por un lado, como ya indicaran Santonja et al. (2000: 532-533), geólogos como J. Royo señalaron críticas al modelo geomorfológico planteado por Pérez de Barradas para el valle del Manzanares, y en consecuencia a la extensa secuencia de niveles musterienses asumida por éste (Royo et al. 1929). Por otro lado, más allá de sus similitudes morfotipológicas, el Esbaikiense norteafricano suponía un paralelo temporal arriesgado para la industria de Las Delicias, pues su cronología se presentó incierta desde su definición por M. Reygasse (Obermaier y Pérez de Barradas 1924: 164; Enamorado 1984; Santonja et al. 2011: 41-42). De esta forma, la nueva interpretación crono-cultural de Las Delicias propuesta a mediados de los años 1920 encuentra su principal explicación historiográfica en el viraje epistemológico que acusó la disciplina desde comienzos de la década. Fue el nuevo marco histórico-cultural, dominado por el particularismo y el difusionismo, lo que de forma más decidida condujo a Obermaier y Pérez de Barradas a plantear el nuevo modelo esbaikiense.

Menos relacionada aún con los datos empíricos resultó la interpretación propuesta en la siguiente década por Pérez de Barradas tras su alejamiento de Obermaier (Santonja et al. 2000: 533). Aunque igualmente desde perspectivas histórico-culturales, Pérez de Barradas (1934b) abandona la influencia norteafricana y, siguiendo el esquema de Breuil, vuelve a relacionar Las Delicias con el Achelense, concretamente con el Achelense VIII o Final. Se trataba pues de un simple cambio de escenario, probablemente relacionable con la nueva posición de influencia de Breuil en la disciplina paleolítica.

Las siguientes referencias a Las Delicias Ilegaron ya en los años 1950. En su trabajo sobre las puntas foliáceas centroeuropeas, G. Freund (1952) relacionó el conjunto industrial del yacimiento madrileño con lo que definió como Presolu- trense. La autora concebía este último como el resultado de una compleja amalgama de influencias culturales achelenses y musterienses que desemboca, a finales del Paleolítico medio, en una industria dominada por las puntas foliáceas bifaciales, similares a las posteriores del Solutrense occidental, pero que incluye también raederas, puntas musterienses y bifaces (Freund 1954). Señala así, apoyándose en un trabajo de Obermaier y Wernert (1929) sobre las puntas del "Paleolítico inferior", las similitudes tipológicas - no solo limitadas a las piezas bifaciales- entre la industria de Las Delicias y aquella de varios yacimientos del centro y el Este de Europa, como Klausennische o Kiik Koba (Freund 1954: 183).

La interpretación de Freund fue recogida por F. Jordá (1955) en su Tesis sobre el Solutrense español, en la que el autor caracterizaba Las Delicias como Presolutrense, y rechazaba las influencias esbaikienses por encontrarse ya entonces "muy alejadas de esa época" (Jordá 1955: 152). Proponía así, junto al Solutrense "propiamente dicho" del valle del Manzanares, la existencia de un "grupo Presolutrense", configurado no solo por Las Delicias, sino también por el nivel c de El Sotillo (con algunas dudas: Jordá 1955: 202) y, siguiendo en esto también a Freund, los areneros de La Parra y Huerto de San Andrés. Sin embargo, Jordá propone una interesante discusión sobre la verdadera cronología de este grupo Presolutrense, y se pregunta si no habría que "rebajarlos en su edad y suponerlos más cercanos o dentro del Paleolítico superior, incluso en relación misma con las forma solutrenses" (Jordá 1955: 154). Es pues Jordá quien primero sugiere, como hipótesis factible, una posible filiación solutrense de Las Delicias.

Resulta también relevante que Jordá (1955: 153) se pregunte el significado de que tanto las industrias presolutrenses -a excepción precisamente de Las Delicias- como las solutrenses, se encontraran, en las terrazas bajas del Manzanares, en los mismos niveles de gravillas, coloquialmente conocidos como "garbancillo". En efecto, muchos de los conjuntos industriales presentes en este nivel de gravillas, que habian sido previamente relacionados por Pérez de Barradas (1926: 105) con el Musteriense ibero-mauritánico, y más tarde con algunas fases del Matritense (Pérez de Barradas 1934a), son caracterizados por Jordá (1955: 154-156) como solutrenses. Tal es el caso de los areneros de Los Vascos, Valdivia (sectores occidental y central), El Cojo y Martínez. El que a su vez considerara presolutrenses, y no solutrenses, algunas industrias presentes en este "garbancillo", como aquellas de El Sotillo, La Parra o Huerto de San Andrés, ha sido explicado en parte por estudios posteriores. Así, en los años 1980 se puso al descubierto que los conjuntos industriales de los niveles de gravillas de El Sotillo y la Parra respondian en realidad a una mezcla de materiales correspondientes a distintos momentos de deposición. Así lo constató A. M. Martínez de Merlo (1984: 64) en el nivel c de El Sotillo, donde identificó dos series industriales distintas, una Musteriense y otra Solutrense, con lo que des- 
echaba además la existencia del Musteriense lberomauritano. Igualmente mezclado se demostró el nivel de gravillas de La Parra, donde sin embargo no pudo reconocerse un componente solutrense - constatándose únicamente industrias del Paleolítico medio- debido a la desaparición de las supuestas puntas tenuifoliadas señaladas por Pérez de Barradas (Enamorado 1989). De hecho, tampoco es seguro que dicho nivel se corresponda con el nivel de "garbancillo" de El Sotillo (Enamorado 1989: 18-19). En el caso de Huerto de San Andrés no contamos aún con una revisión en profundidad de su industria, por lo que no conocemos si su caracterización como Presolutrense, heredada de su definición previa como Musteriense iberomauritano con puntas tenuifoliadas esbaikienses (Obermaier 1925: 204), obedece también a una mezcla de materiales de distinta cronología, o quizá a otra circunstancia relacionada con la funcionalidad de las ocupaciones. Como comprobaremos posteriormente, esta última posibilidad ha de aplicarse al caso de Las Delicias, cuya atribución al Presolutrense se explica por la propia caracterización del conjunto industrial como el resultado de la actividad de talla en un taller lítico $-y$ por tanto sin apenas productos configurados que permitieran su asignación tipológica al Solutrense-, y no como consecuencia de una mezcla de materiales. Tampoco por corresponder, como sostenía Jordá y el resto de investigadores analizados, a un episodio industrial anterior -o muy anterior- a los conjuntos solutrenses presentes en el "garbancillo" del Manzanares. En todo caso, y a pesar de que como comprobaremos más adelante las nuevas excavaciones han puesto al descubierto varios niveles de gravillas en Las Delicias, éstos no deben correlacionarse con el "garbancillo" de la terraza de $+8 \mathrm{~m}$ del Manzanares, pues su posición morfoestratigráfica es muy distinta y no contamos con elementos para establecer una correlación entre ambas posiciones.

Las siguientes revisiones de Las Delicias provienen ya desde perspectivas teórico-metodológicas bordesianas y procesuales (Vega 2001; Alcaraz-Castaño 2014). Así, L. Freeman (1975: 683 y ss.) vuelve a relacionar la industria del yacimiento con el Achelense superior, si bien señala paralelos tipológicos con el Musteriense de Tradición Achelense cantábrico. Su atribución se basaba no solo en la revisión tipológica de la industria, sino en la asunción de que el yacimiento se situaba en la terraza de $+15 / 25$ m (Freeman 1975: 693-694), lo cual pronto se revelaría erróneo. Si otras referencias a Las Delicias efectuadas a comienzos de los años 1980 (Santonja y Querol 1980; Rus 1987: 28) aportaron aún pocas novedades sobre la interpretación del yacimiento, la revisión planteada por M. Santonja et al. (2000) supuso el punto de partida definitivo a partir del cual organizar un nuevo proyecto de investigación para Las Delicias.

En este último trabajo se analizaron historiográficamente las interpretaciones sobre el yacimiento, se estudiaron las escasas piezas (38) de Las Delicias conservadas en el Museo Nacional de Ciencias Naturales, y se planteó una nueva interpretación geomorfológica del depósito, proponiendo un nuevo proceso de formación para el yacimiento a partir de la inspección de su entorno. En efecto, Santonja et al. (2000: 535-536) señalan que Las Delicias, en contra de lo que se creía hasta entonces, no se enmarca en el sistema de terrazas del Manzanares, sino en un área de interfluvio donde no se reconocen depósitos de terrazas. Indicaban así que el depósito tendría un origen local, en un medio tractivo episódico que habria movilizado y reorganizado los materiales dispersos por su pequeña cuenca. Como comprobaremos en el siguiente epígrafe, esta interpretación preliminar ha sido confirmada y ampliada por los resultados obtenidos en las nuevas excavaciones. En cuanto a la atribución crono-cultural de la industria lítica, los autores resaltan lo incierto de cualquier asignación, especialmente por tratarse de una colección seleccionada. Sin embargo, se inclinan por mantener una cronología antigua para el conjunto de Las Delicias, quizá Achelense superior o Musteriense, basándose para ello en la presencia de tecnología levallois y, especialmente, en la morfología de las piezas bifaciales conservadas. Así, aunque reconocen lo atípico del conjunto, así como la posible presencia de técnicas de talla mediante percutores blandos en la configuración de lo que consideran bifaces, las dimensiones y morfología de éstos, en muchos casos simétrica en los ejemplares acabados, les lleva a cuestionar su posible caracterización tipológica como puntas, y con ello una hipotética cronología solutrense del conjunto. Señalan también que la configuración de los utensilios retocados -entre ellos varias raederas- y el estilo del retoque no son propios del Paleolítico superior (Santonja et al. 2000: 539). En cuanto a la interpretación funcional del yacimiento, aceptan, a falta de su confirmación sobre el terreno, su caracterización como taller propuesta por Obermaier y Wernert (Santonja et al. 2000: 540). Tanto las interpretaciones sobre la geomorfología, como aquellas referidas a la industria, fueron presentadas por Santonja et al. como hipótesis preliminares sobre las que construir un futuro proyecto de investigación para Las Delicias.

De forma paralela, J. Baena et al. propusieron una última atribución crono-cultural para Las Delicias. Estos autores plantearon el posible carácter solutrense de la industria en función de las características técnicas de su material bifacial, que relacionaban con soportes abandonados en el proceso de adelgazamiento. Indicaban así que las morfologías poco canónicas y los considerables espesores de buena parte de estas piezas bifaciales podían relacionarse con las primeras fases del proceso de reducción de productos foliáceos solutrenses (Baena et al. 2000: 90; Baena y Carrión 2002: 84; Conde et al. 2000: 152).

El proyecto de investigación que presentamos a continuación debe considerarse una continuación directa de los objetivos y planteamientos teórico-metodológicos propuestos por Santonja et al. a principios del siglo XXI, pudiendo por tanto entenderse como el primer intento, aún preliminar, de resolver los interrogantes planteados entonces (Santonja 
et al. 2000: 541). Sin embargo, el equipo interdisciplinar diseñado para reactivar la investigación en Las Delicias, dirigido sobre el terreno por tres de los firmantes (M. S., A. P-G. y J. M.), se ha configurado valorando las diversas interpretaciones sobre la naturaleza del conjunto industrial que se encontraban activas en el momento de su formación. Con ello se ha pretendido desarrollar un proyecto científicamente abierto, capaz de contrastar las diversas hipótesis que a comienzos del siglo XXI estaban planteadas.

\section{UN NUEVO PROYECTO PARA LAS DELICIAS}

\subsection{Objetivos}

Como acabamos de señalar, los objetivos generales del nuevo proyecto de investigación en Las Delicias se han centrado, en una primera fase, en resolver los interrogantes ya planteados por Santonja et al. (2000: 541):

1. Resolver la problemática cronológica del yacimiento.

2. Resolver la hipótesis que caracteriza el tipo de ocupación como taller y conocer las estrategias de aprovisionamiento de la materia prima.

3. Caracterizar las técnicas de talla y cadenas operativas a las que responde el conjunto industrial.

Asimismo, una vez controlada la asignación del conjunto industrial al tecnocomplejo solutrense (sección 3.2.), nos propusimos un cuarto objetivo:

4. Valorar el papel de Las Delicias en el contexto de la ocupación humana de la Meseta durante el Paleolítico superior, y en concreto bajo las condiciones ecológicas del Estadio Isotópico Marino 2.

Para dar respuesta a estas cuestiones hemos planteado el estudio geoarqueológico, cronométrico y paleoambiental del depósito sedimentario y su entorno inmediato, así como el análisis tecnológico de la industria lítica recuperada en las nuevas excavaciones. En este trabajo, en el que presentamos los primeros resultados, aún preliminares, nos centraremos en el contexto geomorfológico y el estudio de parte de la industria, pues los análisis cronométricos y paleoambientales se encuentran aún en proceso de elaboración.

\subsection{Localización geográfica y trabajos arqueológicos desarrollados}

La localización actual del yacimiento de Las Delicias se enmarca en el centro de la ciudad de Madrid, a unos $200 \mathrm{~m}$ en sentido sur de la actual estación de tren (Cercanias) de
Delicias y al norte del Museo del Ferrocarril, en un extenso solar localizado entre ambos lugares (Fig. 1).

La excepcional circunstancia de que la topografía del área en torno al yacimiento haya subsistido con escasas modificaciones hasta la actualidad (Figs. 5 y 6), preservando los niveles pleistocenos, ha permitido realizar una nueva excavación arqueológica en el yacimiento. Se ha derrumbado el almacén cuya construcción determinó la intervención original, pero los terraplenes inmediatos permanecen en un estado similar al de 1917 (Fig. 5). Los primeros trabajos arqueológicos comenzaron en diciembre de 2008, y consistieron en la realización de doce sondeos mecánicos, de $3 \times 2 \mathrm{~m}$, en ambos extremos y en el centro del solar libre de edificaciones. La finalidad inmediata de los mismos era reconocer si subsistía yacimiento y establecer su extensión, aportando a la vez una primera información sobre la estratigrafía y el proceso de formación del depósito, así como sobre la densidad y características básicas de la industria lítica. La localización de niveles arqueológicos con industria lítica en estratigrafía en cuatro de los sondeos (números 2, 4, 5 y 6) motivó la ampliación de los mismos y la elaboración de un proyecto de excavación sistemática en dos áreas distintas (Sectores I y II). Éste se llevó a cabo en tres campañas sucesivas entre diciembre de 2008 y julio de 2009 (Fig. 6).

En el Sector I, muy próximo a la trinchera del ferrocarril de Cercanías, se abrió un área de $10 \mathrm{~m}^{2}$ en superficie, hasta alcanzar las arcillas neógenas del sustrato geológico, situado a 1,25 m de profundidad. Previamente se rebajaron manualmente $0,65 \mathrm{~m}$ de rellenos antrópicos (nivel I) hasta llegar a los niveles cuaternarios (niveles Ila, Ilb, Ilc y IId) (Fig. 8).

El Sector II se encuentra próximo al antiguo almacén -del que aún queda en pie uno de sus muros (Fig. 5) - y por tanto puede considerarse prolongación del área excavada por Obermaier y Wernert (Fig. 6). En esta zona, que corresponde a la ampliación del sondeo 5 , aún se rebajaron por medios mecánicos $0,8 \mathrm{~m}$ de rellenos antrópicos, además de otros $0,8 \mathrm{~m}$ de limos arcillosos correspondientes al nivel 2 -que abarca la secuencia superior-y parte del nivel 3 -que coincide con el techo de la secuencia inferior-, donde apenas se localizaron restos de industria lítica (Fig. 8). Tras conseguir una plataforma apropiada de $105 \mathrm{~m}^{2}$ se procedió a la excavación manual de los niveles basales (3b y 4), en un área de $13 \mathrm{~m}^{2}$ durante la primera campaña (marzo-abril) de 2009, y posteriormente de $7,5 \mathrm{~m}^{2}$ más en una segunda campaña (junio-julio del mismo año), alcanzando una profundidad máxima respecto a la superficie de $2,5 \mathrm{~m}$.

Además del estudio arqueológico, estratigráfico y geomorfológico del yacimiento, el proyecto de excavación ha incluido la recogida de muestras de sedimento para dataciones numéricas (OSL y C-14) y análisis micropaleontológicos, sedimentológicos y polínicos. Como ya hemos indicado, los datos referidos a estas analíticas se encuentran aún en proceso de estudio. 


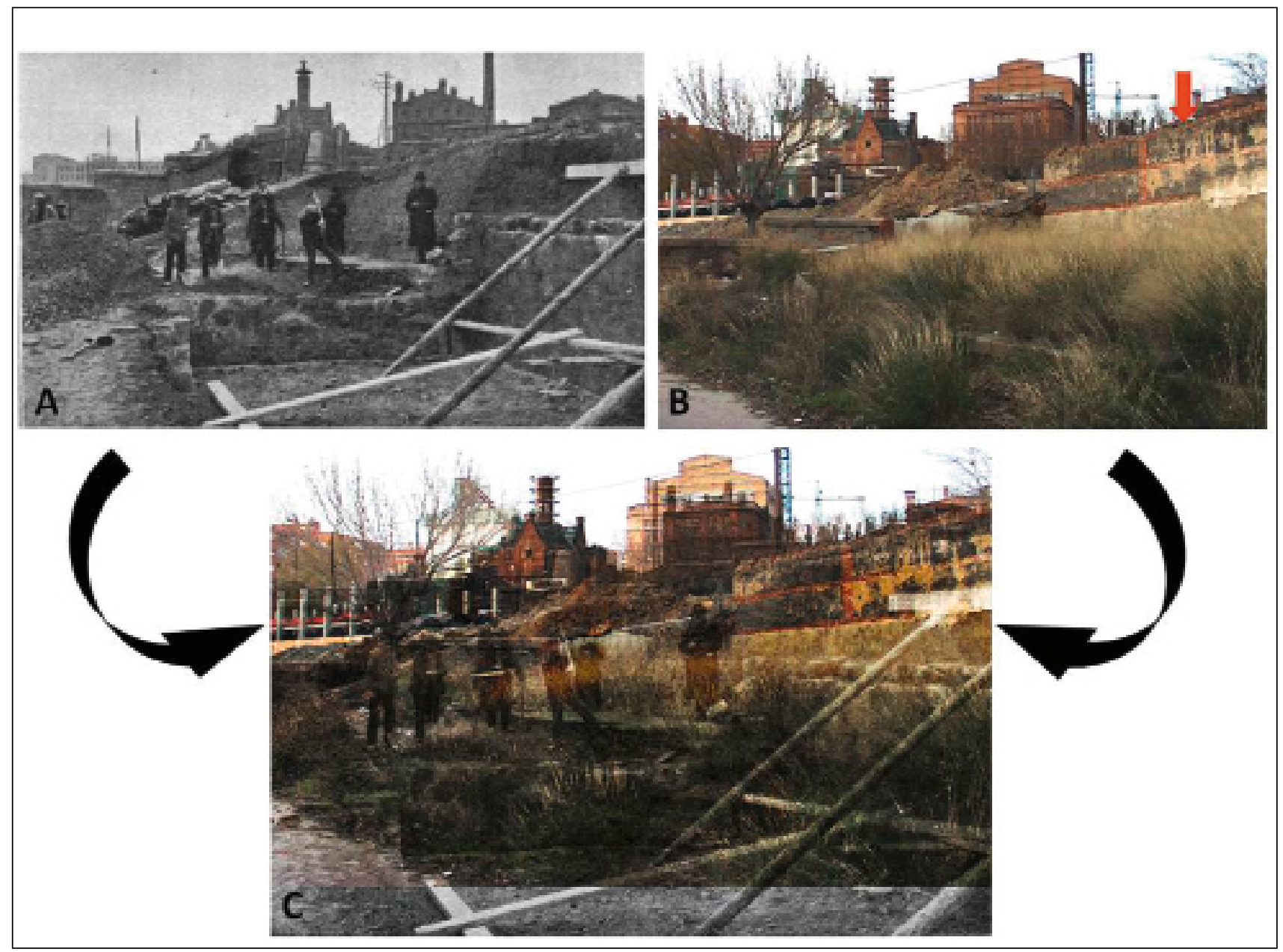

A FiguRA 5. Composición fotográfica (C) a partir de la ilustración original del proceso de excavación en Las Delicias (A) (Obermaier y Wernert 1918: fig. 4) y el estado del solar en la actualidad (B) (Fotografía: Javier Baena). Se comprueba la pervivencia del sitio durante casi un siglo. La flecha roja indica el muro justo detrás del cual se localiza la excavación del Sector II.

\section{LOS PRIMEROS RESULTADOS}

\subsection{Contexto geomorfológico y estratigrafía}

Los depósitos de Las Delicias se enmarcan en una pequeña área deprimida de carácter semiendorreico, ubicada a mitad de ladera entre la llanura aluvial del Manzanares y una alargada superficie que hace de interfluvio entre este río y el antiguo arroyo Carcavón (Royo et al. 1929), tributario del arroyo Abroñigal. El curso de este último arroyo y los de sus afluentes conformaron parte de la red de drenaje secundaria del río Manzanares tras su paso por el tramo urbano de la ciudad de Madrid. A partir del último cuarto del siglo XX, estos pequeños cauces quedaron soterrados y sus cursos de agua canalizados debido a la continua expansión urbanística y a la construcción de la carretera de circunvalación M-30.

La morfología del terreno que caracteriza el entorno de la zona de estudio fue generándose a partir de la continua incisión de la red de drenaje cuaternaria sobre las planicies de la denominada "Superficie de Madrid" o "Rampa de Madrid" (Vaudour 1979), desarrolladas sobre las arenas arcó- sicas miocenas del Aragoniense superior (unidad 11 según Calvo et al. 1989). Estas formas de erosión son coetáneas en su génesis con las primeras terrazas del sistema JaramaHenares, por lo que son posteriores a la raña, y de edad Pleistoceno inferior (Pérez-González 1994). Hacia el final de este periodo se activa en la cuenca del Manzanares el encajamiento de toda su red de drenaje, dando lugar a un sistema de terrazas del Pleistoceno medio y superior por debajo de los $+40 \mathrm{~m}$ de cota relativa sobre el cauce actual del río, desarrollado especialmente en la margen izquierda del Manzanares (Goy et al. 1989).

Según la cartografía consultada, tanto la topográfica histórica (Tardieu 1820 y Ayuntamiento de Madrid 1929), como las distintas ediciones de la cartografía geológica de la hoja 559 de Madrid a escala 1:50.000 del IGME (Royo et al, 1929; Goy et al. 1989) y la cartografía geológica continua actualizada del Plan GEODE 2011, los sectores excavados se sitúan a +16/20 m sobre el cauce actual del Manzanares, en la zona semiendorreica a mitad de ladera señalada más arriba. Esta explanada ligeramente deprimida ha sido modelada a favor de las arcillas verdegrisáceas y azuladas 


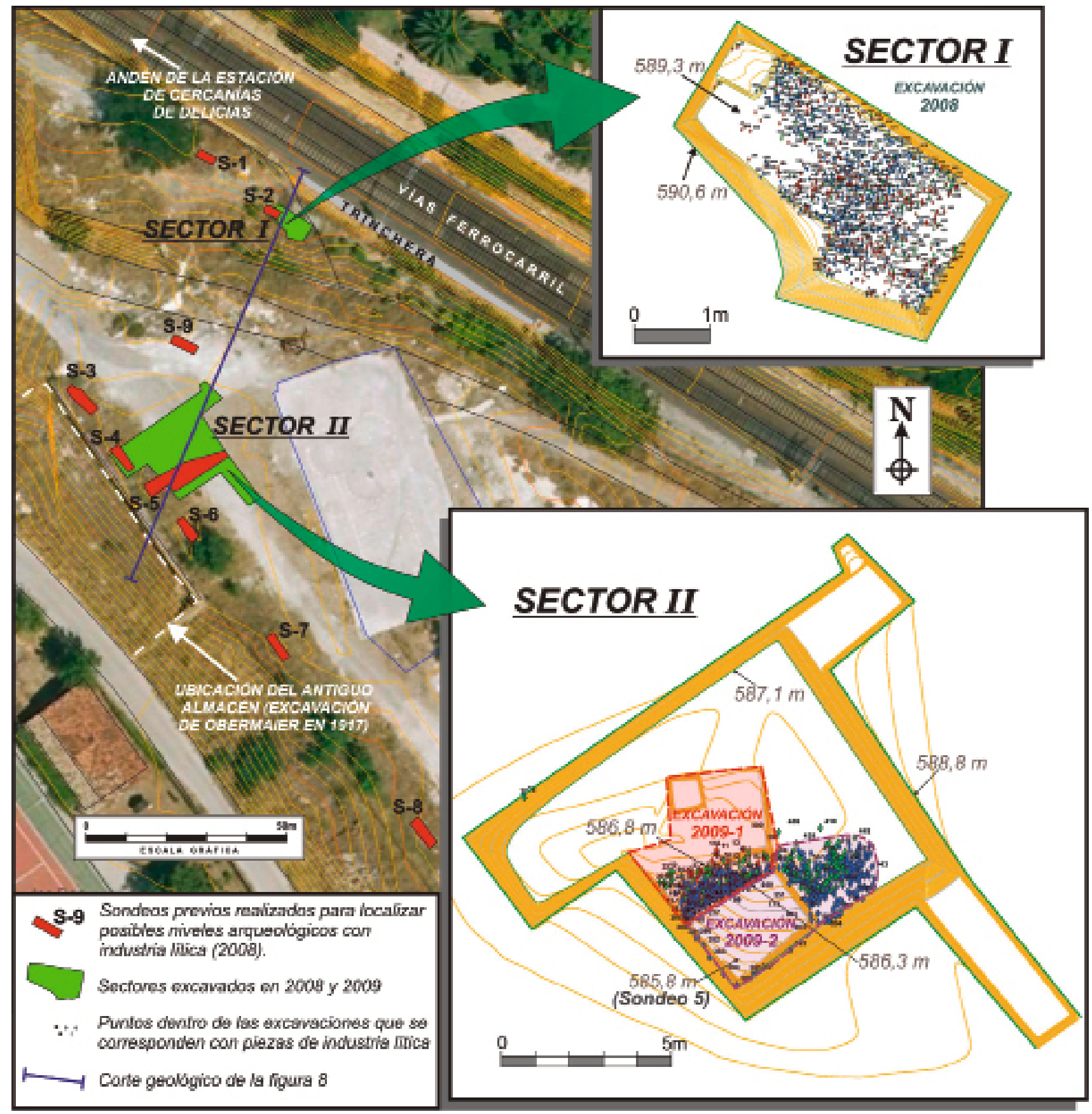

\ Figura 6. Localización de los sondeos mecánicos y excavaciones sistemáticas realizadas en el yacimiento solutrense de Las Delicias (Madrid) durante las campañas de 2008 y 2009.

miocenas de la unidad 6 (Fig. 7), y sobre ella se ha desarrollado un fondo semiendorreico de unas 6 hectáreas. Hacia dicho fondo drenaban regueras originando pequeños abanicos aluviales, constituidos por materiales mal estructurados y con tamaños heterométricos procedentes de las laderas erosionadas por estos cursos esporádicos. Aparecen así cantos de carbonatos, sepiolita, cantos blandos y sílex, incluyendo piezas talladas. Estos materiales proceden del desmantelamiento efectuado por las regueras sobre los niveles con estas litologías, que se encuentran a techo de las arcillas verdegrisáceas y tanto a base como a techo de las arcillas marrones de la unidad de transición con las arcosas. En concreto, en el mapa geológico adjunto (Fig. 7) se han representado posibles localizaciones de afloramientos de silex o carbonatos silicificados, interpretados a partir de la existencia de un nivel de sílex situado a una cota de 603,7 m sobre el nivel del mar (s. n. m. ). Nuestro conocimiento de dicho nivel proviene tanto de su documentación en un sondeo geotécnico realizado en 1989 para el entonces futuro proyecto de ampliación de vías de la Estación de Atocha dentro de la plataforma del Cerro de la Plata, como de la descripción geológica que hacen de él Royo et al. (1929), 


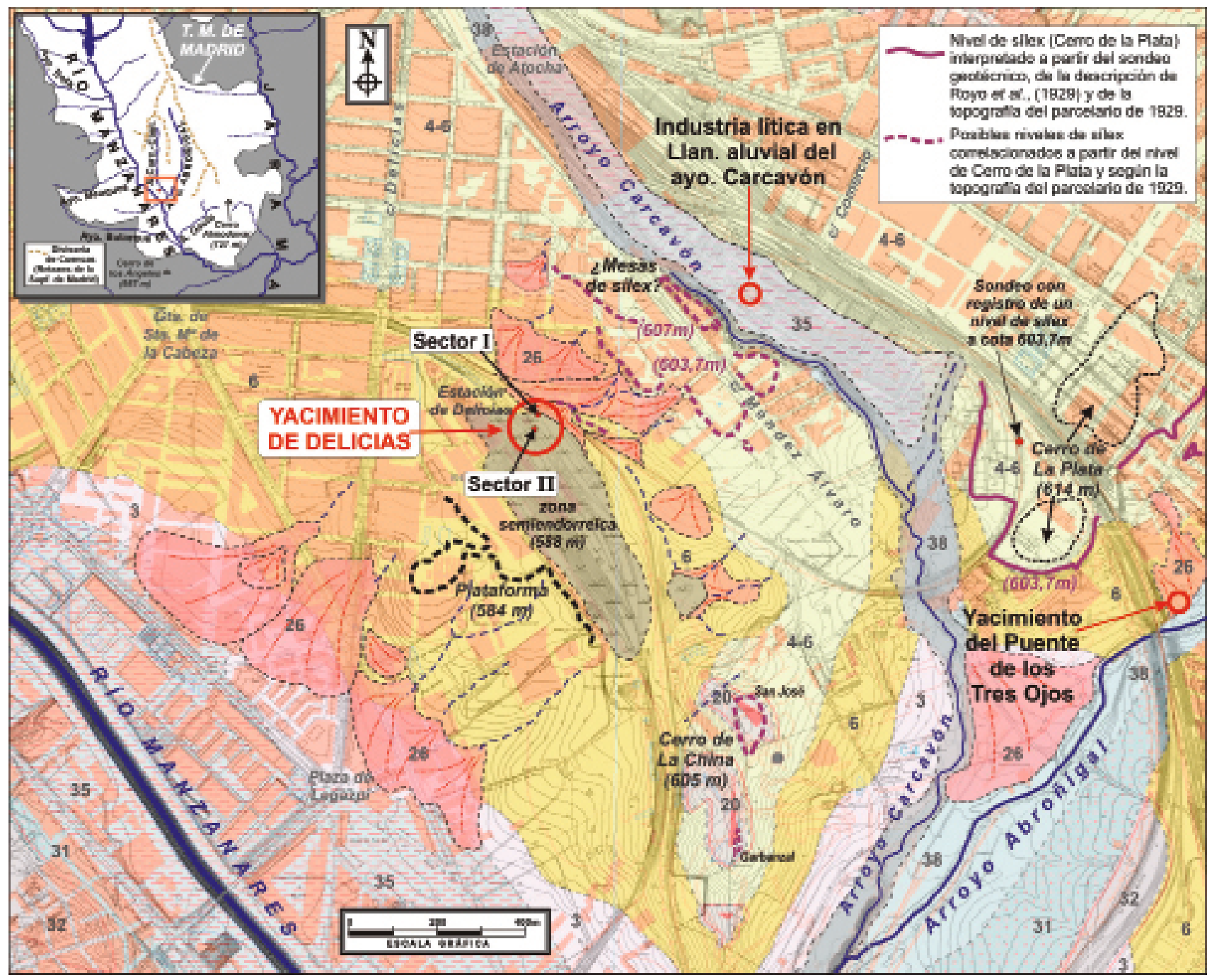

A Figura 7. Mapa geológico y geomorfológico del entorno del yacimiento solutrense de Las Delicias (Madrid). Sobre la base de la cartografía geológica continua 1:50.000 del sistema SIGECO (IGME, 2005-2011) y la base topográfica del Plano parcelario de Madrid, escala 1:2.000 (Ayuntamiento de Madrid 1929), se han añadido la cartografía geomorfológica del entorno inmediato al yacimiento de Las Delicias, así como la localización de posibles afloramientos de sílex y yacimientos paleolíticos próximos. Entre estos últimos se señalan el yacimiento de Puente de los Tres Ojos (Tapias et al. 2012) y la llanura aluvial del Carcavón (Tapias et al. 2011). La leyenda de las unidades geológicas es la siguiente, tomando como referencia la numeración empleada en la hoja geológica 559 a escala 1:50.000 correspondiente a Madrid (Goy et al. 1989; Calvo et al. 1989): - Depósitos cuaternarios: 38: Fondos de valle (Holoc.). 35: Llanuras aluviales (Pleist. sup.-Holoc.). 32: Coluviones (Holoc.). 31: Terrazas bajas (Pleist. sup.). 29: Fondos semiendorreicos (Pleist. sup.-Holoc.). 26: Abanicos aluviales (Pleist. sup.-Holoc.). 20: Glacis (Pleist. inf.-med.). - Depósitos terciarios del Mioceno medio: 6: Arcillas verdes con niveles de carbonatos y de sílex. 4-6: Arcillas y limos arcósicos con niveles de carbonatos y sílex (transición entre unidades 4 y 6). 4: Arenas gruesas y limos arcósicos. 3: Arcillas verdes y marrones.

en la que diferencian tres niveles de carbonatos ocasionalmente silicificados. La cota en la que se ha documentado este nivel de silex coincide, según la topografía del Plano Parcelario de Madrid (1929), con áreas donde las curvas de nivel aparecen más próximas, como es el caso de la zona situada $200 \mathrm{~m}$ al NE de los sectores excavados. Esta metodología es la única que se ha podido aplicar para ubicar las posibles zonas de captación del silex tallado en Las Delicias, ya que no poseemos más datos geológicos o geotécnicos de estos niveles en el entorno inmediato del yacimiento.

El área semiendorreica descrita mantenía un escaso drenaje exterior, condicionado posiblemente por la esporádica colmatación de esta pequeña vaguada, cuyo rebose liberaría agua hacia la vertiente izquierda del Manzanares en el entorno de la actual calle Embajadores al oeste de la Plaza de Legazpi (Fig. 7).

Los sectores excavados en Las Delicias se encuentran en una zona más externa dentro del citado fondo semiendorreico, situándose al pie de los conos aluviales que llegarían a esta ligera hondonada. El Sector I se encuentra en una posición más elevada y exterior que el Sector II, posiblemente como consecuencia de la existencia de cierto escalonamiento entre los depósitos de los dos sectores (Fig. 8).

En el Sector I, tras un primer nivel (I) a techo, compuesto por rellenos antrópicos recientes con una cota superior de 590,6 m s.n.m, se documentaron varios niveles estratigrá- 


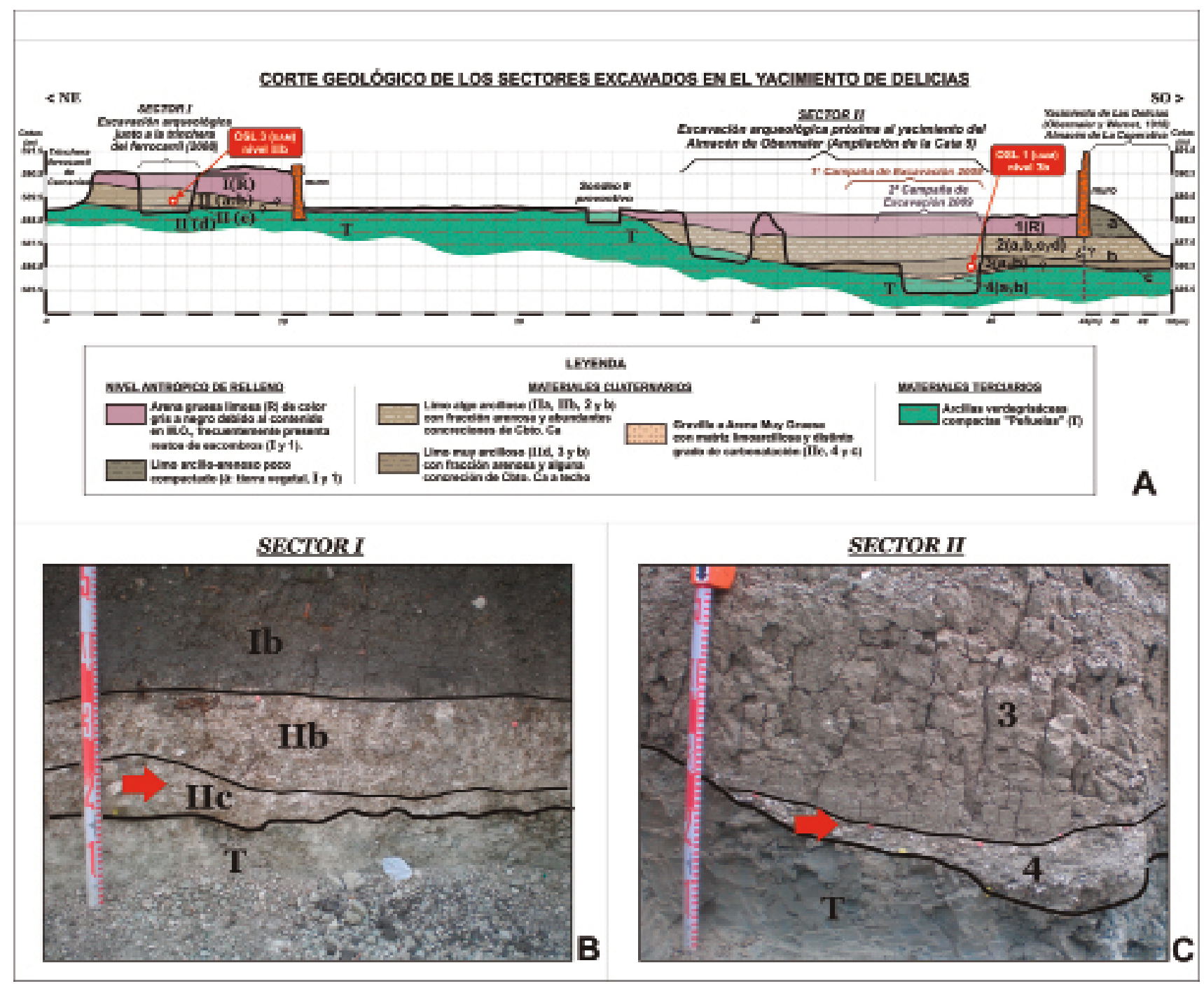

\ FiguRA 8. A. Corte geológico y estratigráfico del yacimiento solutrense de Las Delicias (Madrid), en el que se muestra la ubicación relativa de los dos sectores excavados y la localización de la antigua excavación de Obermaier y Wernert; B. Estratigrafía del Sector I; C. Estratigrafía del Sector II. Las flechas marcan los niveles IIc y IV respectivamente. Fotografías: Mario López-Recio y Fernando Tapias.

ficos cuaternarios a partir de la cota 589,95 m s.n.m, con una potencia máxima de $0,6 \mathrm{~m}$. Estos niveles, que se acuñan casi en su totalidad hacia el Sur en escasamente $2 \mathrm{~m}$, se componen en su mayor parte de limos arcillosos, con cierto porcentaje de fracción arenosa y de gravilla, según determinaciones macroscópicas de campo. Se distinguen así, según la cantidad de concreciones carbonáticas, los niveles Ila y llb (Fig. 8. A y B). Bajo estos últimos existe un pequeño nivel de gravillas matriz-soportadas (nivel Ilc) con fuerte cementación carbonática, compuesto por materiales de distinta granulometría y composición que han sido transportados en un medio acuoso, sin selección ni clasificación en el proceso de sedimentación. Por último, se ha documentado un fino nivel de limo arenoso (IId) de escasa continuidad que, junto con las gravillas (IIc), está en contacto erosivo con las arcillas verdosas neógenas del sustrato (nivel T), que aparecen a una cota de 589, $3 \mathrm{~m}$ s.n.m. Se registra industria lítica en todo el nivel II, aunque la gran mayoría de las piezas recu- peradas proceden de los subniveles Ilb y llc. En Illb se tomó una muestra para datación numérica (OSL-3) a $10 \mathrm{~cm}$ de su base, cuyo resultado se encuentra aún en proceso.

En el Sector II, contiguo a la excavación de 1917 y en una posición inferior a la del Sector I (Figs. 6 y 8), se han documentado varios niveles estratigráficos cuaternarios que responden, en líneas generales, a los documentados por Obermaier y Wernert. La potencia máxima de estos niveles, a lo largo de la alineación NE-SO, llega hasta los 1,85 $\mathrm{m}$ hacia el perfil suroeste de la excavación, acuñándose lateralmente hacia el Noroeste y Sureste hasta los 1,3 y 0,8 $\mathrm{m}$ de espesor en escasamente 3 $\mathrm{m}$ de longitud. Parece que los niveles estratigráficos basales se disponen a lo largo de una pequeña vaguada o reguero que drenaba hacia el Suroeste, según indica también el paleorrelieve compuesto por las arcillas del sustrato neógeno (Fig. 8). A techo, bajo un primer nivel (1) de rellenos actuales, acotado entre 588,8 y $587,95 \mathrm{~m}$ s. $n$. $\mathrm{m}$, la estratigrafía de este sector está representada por un nivel 2 compuesto por limos arcillo- 
sos con distinto grado de concreciones carbonáticas (niveles $2 a, 2 b$ y $2 d$ ) y ocasionalmente por pequeños niveles o hiladas de gravilla de escasa continuidad (nivel 2c). Bajo ellos se documenta, a una cota media de 587,15 m s. n. m, un tercer paquete en el que se diferencia un limo muy arcilloso (nivel 3a) y otro limo arcilloso (nivel 3b), diferenciados ocasionalmente por alguna hilada de gravillas. El nivel $3 b$, en el que se ha recuperado cierta cantidad de industria lítica, presenta una potencia máxima de $30 \mathrm{~cm}$ y se compone de limos arcillosos con poca fracción arenosa y color marrón oliva grisáceo (Hue 5 Y 5/3). Presenta cierta compactación y también planos de fractura estriados ("lisos" o "slickenside"), y se acuña hacia el noroeste de la excavación hasta desaparecer. Ocasionalmente se ve atravesado por alguna hilada de arenas o gravillas de no más de $1 \mathrm{~cm}$ de espesor y escasa continuidad lateral $(30 \mathrm{~cm})$. En este nivel, que ha de corresponderse con la base del nivel $b$ de Obermaier y Wernert, se tomó una muestra para datación numérica (OSL-1) a $10 \mathrm{~cm}$ de su base, cuyo resultado aún no está disponible.

Hacia la base de la excavación aparece un paquete de entre 20 y $30 \mathrm{~cm}$ de espesor (nivel 4) compuesto por pequeños niveles de gravillas matriz-soportadas y otro intermedio de limos que se disponen en forma de "U" abierta al tratarse del fondo de un pequeño canal o reguero con sentido 0-SO (Fig. 8. A y C). Este nivel, en el que se documenta la mayor parte de la industria de este sector, varía su cota altimétrica lateralmente entre 586,8 y 585,8 $\mathrm{m} \mathrm{s}$. $n$. $m$, amoldándose al contacto erosivo con las arcillas del sustrato terciario (nivel T) y llegando a las cotas más altas hacia el NE de la excavación. Los niveles de gravillas presentan un espesor variable entre 5 y $7 \mathrm{~cm}$, que en algunos puntos llega incluso a $13 \mathrm{~cm}$, y suelen estar compuestos por carbonatos, aunque también sílex y ocasionalmente cuarzo, cuyos tamaños, heterogéneos, oscilan entre los 0,2 y 0,4 cm de diámetro. Existen algunos cantos de mayor tamaño, entre 0,6 y $4 \mathrm{~cm}$ (centil de $8 \mathrm{~cm}$ ), con las mismas composiciones y porcentajes que las gravillas. La matriz está constituida por limos arcillosos de color gris oliva a marrón, no apareciendo cementos carbonáticos como sí ocurre en el Sector I. Estas gravillas matriz-soportadas tienen una menor abundancia y tamaño de grano que las documentadas en el otro sector. Es un nivel compuesto por materiales de distinta granulometria y composición, transportado sin apenas selección ni clasificación en un medio fluvial. La mayoría de la industria lítica se documentó en el nivel de gravillas superior.

Es probable que este nivel 4 se corresponda con la capa c de Obermaier y Wernert. De esta forma, debemos tener presente que lo que los mencionados investigadores consideraban un solo nivel de ocupación, el "verdadero yacimiento" situado en la base de su nivel b y la capa c (ver secciones 1.1. y 1.2.), son en realidad dos niveles estratigráficos distintos ( $3 b$ y 4 ), depositados por el medio en dos momentos diferentes.
La falta de continuidad estratigráfica entre ambos sectores de Las Delicias, unida a la importante alteración topográfica que ha sufrido esta zona por la actividad humana en el último siglo, suponen un problema para la comprensión geoarqueológica del yacimiento. Sin embargo, teniendo en cuenta los datos geomorfológicos, altimétricos y composicionales obtenidos, podemos interpretar que los sedimentos se disponen en dos niveles de depósitos escalonados con una diferencia altimétrica de $+3 \mathrm{~m}$. Ello indicaria la existencia de dos depósitos separados por un encajamiento dentro de este fondo semiendorreico colgado en la vertiente izquierda del tramo urbano del Manzanares. Podemos inferir, por tanto, que los niveles superiores (Sector I) tendrían una edad más antigua que los inferiores (Sector II), inferencia que las dataciones por OSL en curso podrán contrastar. La industria que contienen dichos niveles superiores, movilizada por estos medios desde posiciones cercanas dentro de la pequeña cuenca drenada, debe poseer por tanto una cronología ligeramente anterior.

Según los primeros resultados del estudio tafonómico de la industria lítica, aunque la alta presencia de roturas marginales y pseudorretoques abruptos en los filos de las piezas del Sector I podría indicar episodios de trampling 0 pisoteo, en ninguno de los sectores se ha documentado un desgaste importante por rozamiento en las piezas a pesar del transporte que han experimentado, que en todo caso debió ser de escaso recorrido.

Las secuencias descritas corresponden a facies fluviales que alcanzan el fondo semiendorreico desde las laderas de la loma o pequeña plataforma que hace de divisoria entre el arroyo Carcavón y el río Manzanares. Se trataría pues de un transporte condicionado por la escasa distancia a la que se encuentran las laderas y por las características de la plataforma donde se encuentra el fondo semiendorreico. Como ya hemos indicado, consideramos la posible existencia en este interfluvio de arcillas terciarias y uno o más niveles de sílex, por lo que la materia prima pudo captarse tanto a partir de los bloques erosionados y arrastrados a favor de la ladera y/o por las regueras aludidas, como en los propios afloramientos situados por encima del yacimiento (Conde et al. 2000). Una posible zona de aporte estaría situada a una distancia de entre 50 y 200 m de los sectores excavados, mientras que la localización más cercana de un posible afloramiento se sitúa hacia el noreste, a menos de $50 \mathrm{~m}$ del Sector I, al otro lado de las vías férreas (Fig. 7). La materia prima se compondría de bloques de sílex de distinto tamaño, tanto más grande cuanto más cercano al afloramiento del que procede.

\subsection{La industria lítica}

Las nuevas excavaciones en Las Delicias nos han permitido recuperar un importante lote de piezas líticas en silex, las cuales constituyen el elemento arqueológico exclusivo del yacimiento. Presentamos a continuación un avance, aún 
preliminar, de los resultados obtenidos en su estudio, para el que nos centraremos en el nivel Ilc del Sector I y el nivel 4 del sector II. Se trata en ambos casos de los niveles que mayor número de efectivos líticos han deparado. En este trabajo nos limitaremos a señalar, desde un punto de vista cualitativo, los elementos industriales que consideramos significativos de cara a la caracterización funcional y crono-cultural de los niveles estudiados, sin entrar aún en datos cuantitativos.

Los conjuntos industriales de los dos niveles responden a patrones tecnológicos similares: la mayoría de piezas, lascas brutas, se enmarcan en las fases de plena producción $y$, en menor medida, de inicio de la talla, mientras que las fases de consumo y abandono apenas están representadas, limitándose a algunos elementos retocados muy minoritarios. Esta circunstancia, unida tanto a nuestras hipótesis de partida como a las consideraciones realizadas por Obermaier y Wernert sobre el material de la excavación original, nos ha conducido a centrar nuestro estudio en las cadenas operativas de producción y la tecnicidad de la muestra. Aunque existen algunas diferencias entre los dos niveles, en ambos se documentan soportes que presentan de forma recurrente una serie de estigmas y atributos característicos que permiten relacionarlos con una tecnología de reducción bifacial (façonnage) de piezas foliáceas, gestionada mediante percutores blandos en sus fases medias y finales: talones lineales, de escasa longitud y habitualmente con un labio pronunciado, ángulos de lascado rectos, restos de abrasión y raspado de las cornisas en los sectores proximales, ausencia de conos de percusión, bulbos difusos o poco marcados, esbeltez generalizada de los soportes, alta presencia de morfologías ovales, y presencia de negativos bidireccionales enfrentados en los anversos de las lascas de menor tamaño. En el contexto del Paleolítico, la aparición sistemática de estas características se documenta únicamente en el Solutrense. En efecto, los rasgos señalados caracterizan las típicas lascas de reducción bifacial de piezas foliáceas, definidas tanto en sitios de talla solutrenses (Aubry et al. 1998; Tiffagom 2006), como a través de la talla experimental (Pelegrin y Chauchat 1993; Baena 1998; Callahan 2000).

Junto con estas "lascas solutrenses", hemos identificado también varios productos bifaciales abandonados en diversos momentos de la reducción, que inciden en el carácter solutrense de ambos niveles. Estas piezas pueden ponerse en relación con las "hachas de mano" o "puntas tenuifoliadas" identificadas por Obermaier et al. (sección 1.2. y Fig. 4), las cuales, desde una perspectiva tecnológica, deben también entenderse como preformas o piezas bifaciales en diversos estadios de reducción, tal como ya había sido apuntado (Baena et al. 2000: 90; Baena y Carrión 2002: 84).

\subsubsection{Sector II: nive/ 4}

En el nivel 4 del sector II hemos documentado 619 piezas en $20,5 \mathrm{~m}^{2}$ excavados (de los que únicamente alrede- dor de 15 resultaron fértiles), 226 de las cuales (el 36,51\%) están fracturadas. Su estado de conservación es óptimo, pues apenas presentan indicios de desgaste o rodamiento ni de otras alteraciones superficiales.

Como ya hemos expuesto, este nivel compuesto por gravillas se corresponde en buena medida con la capa c de Obermaier y Wernert (Fig. 3), cuyas industrias, junto a las de la base de su capa $b$-que nosotros correlacionamos con el nivel $3 b$ reconocido en nuestra intervención (Fig. 8)-, fueron las que originalmente definieron como "Achelense final clásico". Si dichos autores, desde una perspectiva tipológica, primaron lo que definieron como "hachas de mano" para caracterizar el lote industrial, el análisis tecnológico ha puesto de relieve la importancia de las numerosas lascas de reducción bifacial presentes en el conjunto. Encontramos así desde lascas pertenecientes a los momentos iniciales de la preconfiguración de los soportes, obtenidas mediante percusión dura, aún espesas y en ocasiones con bordes escuadrados y restos de córtex, hasta las mencionadas "lascas solutrenses", características de estadios más avanzados de la reducción bifacial (Fig. 9. 1, 2 y 3). Junto a ellas hemos documentado varios soportes en estadios iniciales de preconfiguración, abandonados por fracturas (Fig. 9. 7.) o procesos de talla inviables (Fig. 9. 8.) y que, al igual que varias de las "hachas de mano" definidas por Obermaier y Wernert y teniendo en cuenta el contexto tecnológico general del conjunto, pueden caracterizarse como preformas de elementos bifaciales solutrenses. En varias de estas piezas se constata un esquema de reducción según el cual, a través de la preparación de planos de percusión, se reduce primero el anverso de la pieza, dejando el reverso para una fase posterior (Fig. 9.7 y 8 ).

Existe también una escasa producción laminar en el conjunto, que en todo caso presenta un carácter ciertamente expeditivo. Así se desprende de la poca estandarización y organización de los escasos núcleos conservados y los productos obtenidos (Fig. 9. 4 y 5), lo cual denota un escaso interés por organizar una producción sistemática de verdaderas láminas. Se trata pues de una producción ocasional, destinada en algunos casos a la fabricación de elementos retocados (que suponen el 2,58\% del conjunto). El carácter expeditivo de estos últimos, poco característico en sentido tipológico, es también constatable (Fig. 9.5 y 6).

\subsubsection{Sector I: nive///C}

En el nivel llc del Sector I se han coordenado 520 piezas en $10 \mathrm{~m}^{2}$ excavados, de las cuales 204 (39,23\%) se presentan fracturadas. Su estado de conservación es bueno, si bien muchas de sus superficies aparecen afectadas por una ligera pátina blanquecina y una capa de carbonatos de origen edáfico, la cual ha sido eliminada mediante una solución de agua y ácido clorhídrico (p.ej. Fig. 10. 8). También se constatan, como ya señalamos (sección 3.1.), algunas roturas marginales y 


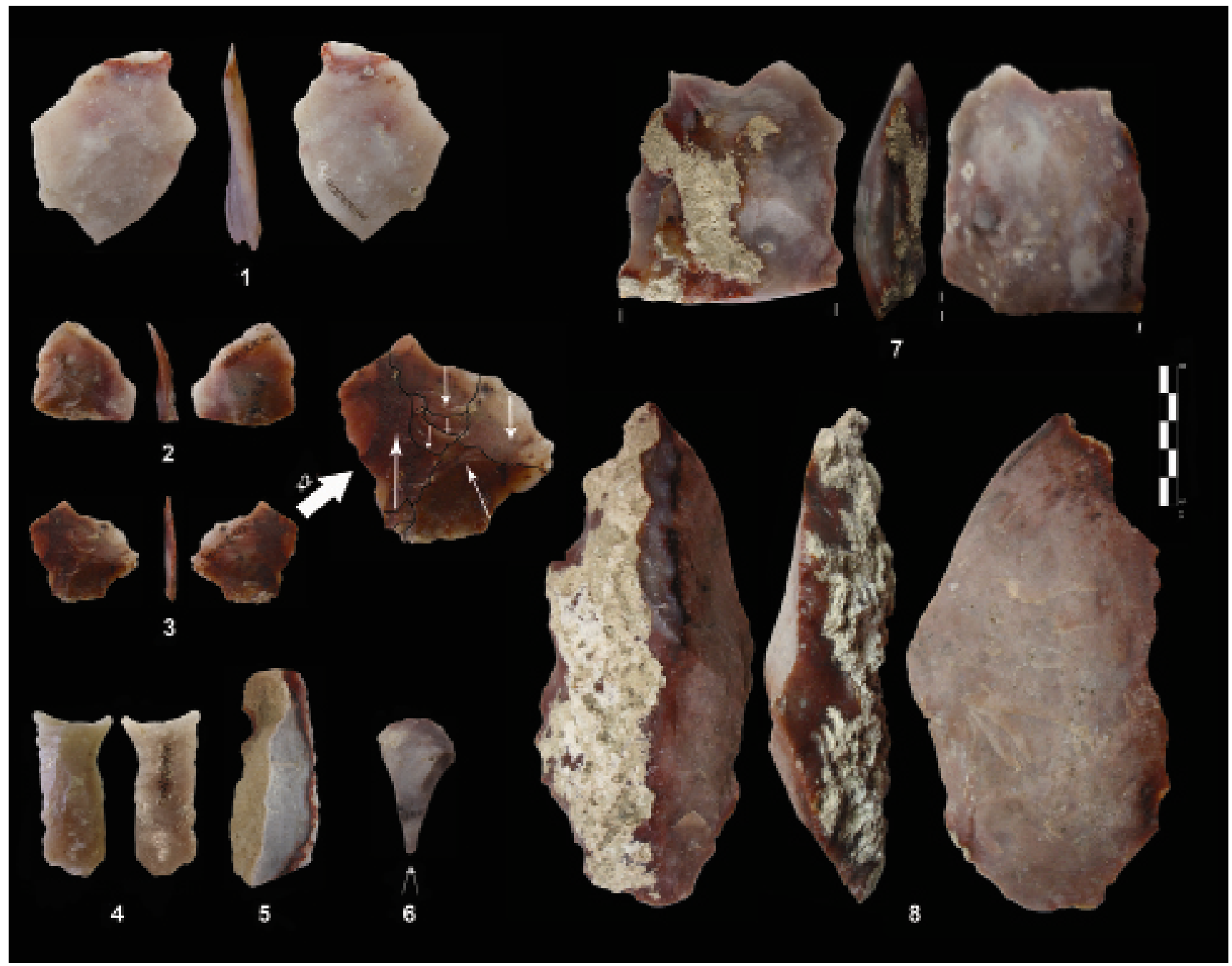

\ FiguRa 9. Industria lítica del nivel 4 (Sector II) del yacimiento solutrense de Las Delicias (Madrid). 1. Lasca de reducción bifacial de gran soporte; 2. Lasca de reducción de fase avanzada con restos de preparación de plataforma; 3. Lasca de reducción de fase avanzada, muy esbelta y con negativos enfrentados en anverso; 4. Lámina de aristas paralelas; 5 . Muesca sobre lámina cortical; 6. Raspador-buril. 7. Preforma de pieza bifacial en fase de configuración inicial, abandonada por fractura; 8. Preforma de pieza bifacial en fase inicial, abandonada por perfiles sinuosos. Fotografías: Manuel Alcaraz-Castaño y Elizabeth Díaz.

pseudorretoques abruptos en los filos, que podrían indicar, a falta de un estudio pormenorizado, procesos de trampling o pisoteo (McBrearty et al. 1998).

De forma aún más mayoritaria que en el anterior nivel, el conjunto aparece dominado por lascas de reducción bifacial (Fig. 10. 1, 2 y 3). También hemos documentado varias piezas bifaciales en distintos grados de elaboración, todas ellas abandonadas antes de su configuración final. Junto a preformas en fases iniciales (Fig. 10. 5.), elementos abandonados por múltiples accidentes (Fig. 10. 6.), o soportes poco aptos para el adelgazamiento (Fig. 10. 7.), destaca especialmente una pieza foliácea en fase avanzada de reducción que, aunque abandonada por una doble fractura, es clasificable como hoja de laurel (Fig. 10. 8.). Se documenta también una escasa producción laminar (Fig. 10. 4.) y los elementos retocados $(1,15 \%$ del total de piezas) son aún más escasos que en el sector II, no habiéndose documentado ningún utensilio en sentido tipológico.

\section{DISCUSIÓN Y PERSPECTIVAS}

Los dos conjuntos industriales estudiados yacen en posición derivada, y aunque la posición morfoestratigráfica de los depósitos en que se encuentran indica que corresponden a momentos temporales diferenciados -distancia cronológica que pretendemos evaluar a través de las dataciones por OSL en curso-, dicha posición no permite concluir si los materiales de ambos sectores proceden de la misma acumulación industrial primaria o de varias, sincrónicas o no a su vez. La proximidad de la ladera y la dinámica de los procesos reconocidos apoyan la hipótesis de que el tiempo transcurrido entre la producción de la industria y su ulterior transporte y deposición no puede ser amplio, y que los conjuntos industriales primarios, originados en la plataforma formada al pie de la ladera antes de ser erosionada, corresponden asimismo a un intervalo temporal reducido. 


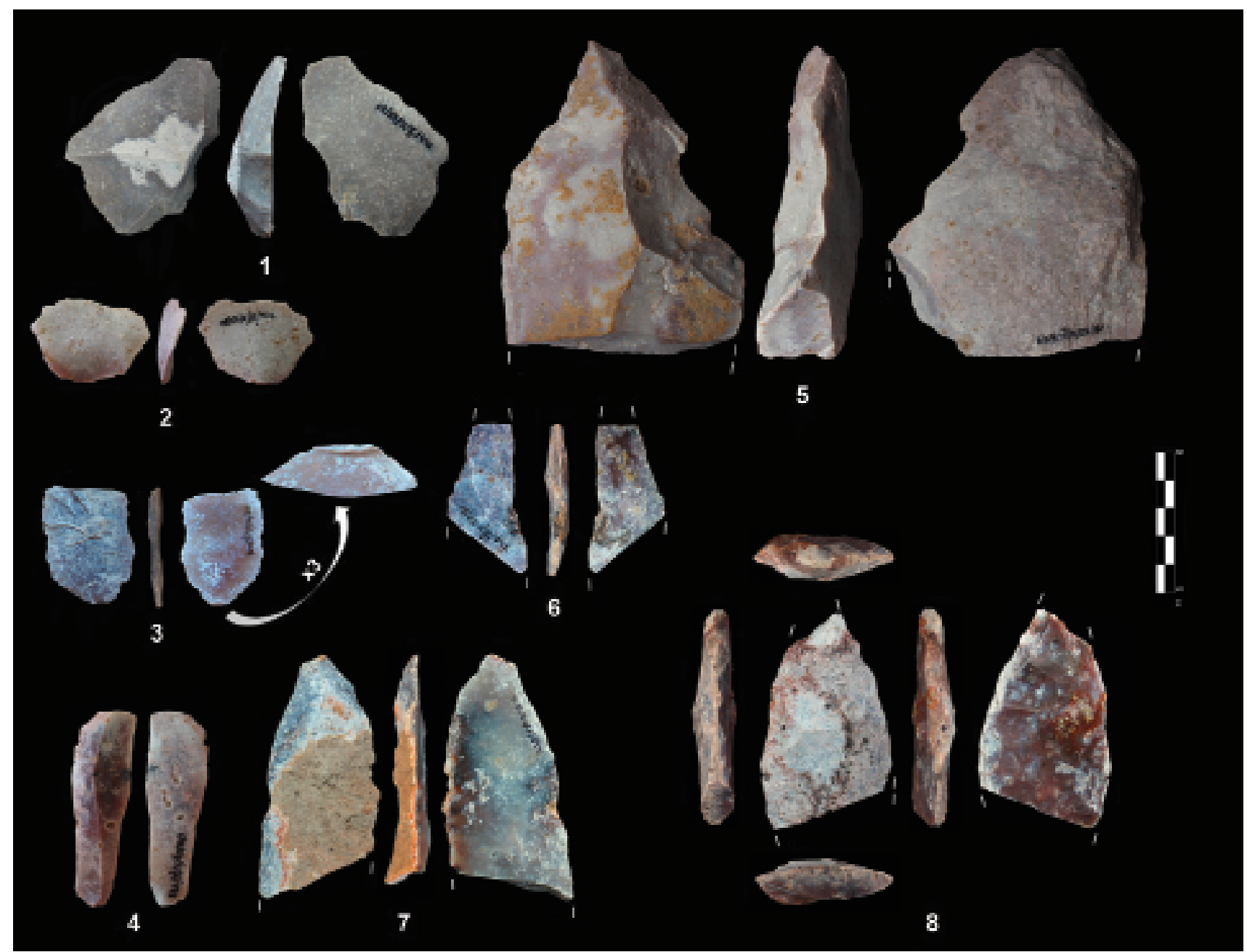

\ Figura 10. Industria lítica del nivel IIc (Sector I) del yacimiento solutrense de Las Delicias (Madrid). 1. Lasca desbordante de primeras fases de la reducción, que elimina un borde escuadrado; 2. Lasca kombewa proveniente del adelgazamiento de un reverso; 3. Lasca de reducción de fase avanzada, reflejada, muy esbelta y con talón labiado muy pronunciado; 4. Lámina; 5. Preforma de pieza bifacial en fase de configuración inicial; 6. Pieza bifacial en fase avanzada, con doble cascada de paros y fracturas distal y oblicua; 7. Lasca cortical fracturada con inicio de adelgazamiento en reverso; 8. Foliácea (hoja de laurel) en fase avanzada de adelgazamiento, abandonada por doble fractura. Fotografías: Manuel Alcaraz-Castaño y Elizabeth Díaz.

Sin embargo, la diferente composición litológica y tecnológica de ambos conjuntos apoya la idea de que los dos niveles estudiados no solo corresponden a dos momentos distintos de deposición, sino que se originaron en dos episodios de producción lítica diferenciados. En efecto, a pesar de que en ambos niveles se documenta un tipo de talla característica del tecnocomplejo solutrense, destinada a la configuración de piezas foliáceas a partir de la reducción bifacial de grandes soportes mediante percusión blanda, existen algunas diferencias significativas entre ambos conjuntos. Mientras que el peso del trabajo bifacial en el conjunto industrial del nivel Ilc (sector I) es abrumadora, y abarca todas las fases de la cadena operativa excepto la captación y el consumo, en el nivel 4 del sector II parece reducirse mayoritariamente a las fases iniciales y medias de la reducción, lo cual además se refleja en una menor -aunque aún significativa- presencia de atributos típicos de percusión blanda, así como en un número más reducido de débris. Por otro lado, la mayor presencia en este último nivel de soportes y núcleos relacionados con métodos de producción de láminas y lascas indica una mayor diversificación de la producción, que no solo se restringiria a la reducción bifacial.

Aunque nuestro estudio aún está en su fase preliminar, nos encontramos ya en disposición de confirmar la hipótesis que caracterizaba Las Delicias como un taller, pues la inmensa mayoría de los productos líticos documentados responden a actividades de talla. La fase de consumo se ve únicamente representada por un número muy limitado de utensilios fabricados de forma expeditiva, cuya presencia en el yacimiento puede explicarse como consecuencia de la necesidad de resolver necesidades puntuales sobrevenidas durante el proceso de producción lítico. En cuanto a la captación de la materia prima, ésta debió realizarse necesariamente en un emplazamiento cercano, ya fuera en el propio afloramiento o en la ladera inmediata. Nos encontrariamos así ante conjuntos derivados de áreas pro- 
bablemente recurrentes de captación y talla, y no solo de talla, similares a otros recientemente identificados en varios emplazamientos paleolíticos madrileños de diferentes cronologías (Baena et al. 2011).

Estos datos, aunque aún deberán verse completados y contrastados por el estudio tecnológico exhaustivo de la industria y los resultados de las dataciones cronométricas y analíticas paleoambientales, permiten cerrar la larga discusión sobre la atribución crono-cultural de la industria de Las Delicias. Desde una perspectiva historiográfica, los nuevos resultados obtenidos a través del análisis tecnológico nos informan de cómo distintas metodologías de investigación pueden desembocar en interpretaciones dispares, y en concreto de las limitaciones que ha presentado tradicionalmente la aplicación exclusiva de la tipología al estudio de las industrias líticas. En efecto, muchas de las "hachas de mano" definidas desde una perspectiva tipológica por Obermaier y Wernert son tecnológicamente similares a varias de las preformas de piezas bifaciales solutrenses presentadas aquí, y de hecho, considerando los nuevos datos, la pieza reproducida en nuestra figura 4 no debería ofrecer dudas en cuanto a su caracterización como foliácea solutrense en fase avanzada de reducción. En general, el conjunto publicado a principios del siglo XX adquiere una significación ciertamente distinta desde la óptica del estudio tecnológico, pues lejos de la visión estática del registro arqueológico asumida por la heurística tipológica, éste plantea un análisis dinámico que resulta ineludible en el estudio de los restos de un proceso de talla, entre los que apenas se encuentran los productos finales buscados por los talladores. En posteriores trabajos incidiremos sobre la reinterpretación de la industria proveniente de la excavación antigua, ocupándonos no solo de las reducciones bifaciales, sino también de las producciones laminares y levallois, así como de los instrumentos retocados definidos por Obermaier y Wernert (sección 1.2).

En todo caso, por el momento es un criterio tecno-tipológico el único que permite conjeturar una asignación cronológica precisa de los conjuntos: la presencia en el nivel IIC de una hoja de laurel remite su conjunto industrial, formado en un momento inmediatamente anterior al depósito reconocido en el Sector II, al Solutrense medio o superior.

Se abre ahora una nueva etapa en la que, una vez resueltos los objetivos relacionados con la posición cronológica y funcionalidad del yacimiento, el estudio de Las Delicias nos plantea numerosos objetivos específicos centrados en la caracterización de sus conjuntos industriales: estrategias de captación y talla, procesos de aprendizaje, grados de destreza o tratamiento térmico, entre otros. Asimismo, desde una perspectiva más amplia debemos también plantearnos las implicaciones que presenta este yacimiento solutrense, el único en el Manzanares excavado con metodología actual y en posición estratigráfica bien definida, para la discusión sobre la ocupación humana de la Meseta durante el Paleolítico superior. La presencia en la cuenca de Madrid de un taller solutrense, muy probablemente encuadrable en el Pleniglacial superior (MIS 2) y próximo al Último Máximo Glacial (Banks et al. 2009), indica una ocupación organizada de este territorio meseteño en esas cronologías, pues si existen sitios de talla especializados debieron existir lugares de consumo próximos. Si a esto le sumamos el resto de evidencias solutrenses en la región, algunas de ellas descubiertas recientemente (Tapias et al. 2012), y especialmente las ocupaciones protosolutrenses y solutrenses relacionadas con actividades cinegéticas documentadas en el abrigo de Peña Capón (valle del río Sorbe, Guadalajara) (Alcaraz-Castaño et al. 2013), el estereotipo clásico de una Meseta desolada o solo frecuentada esporádicamente hasta el Tardiglacial se ve definitivamente refutado, al menos en lo tocante a la vertiente sur del Sistema Central. El avance que aqui hemos presentado supone solo el inicio de futuras investigaciones sobre Las Delicias, las cuales sin duda arrojarán luz sobre la ocupación del interior de la Península lbérica durante el tramo central del Paleolítico superior.

\section{AGRADECIMIENTOS}

La intervención arqueológica en Las Delicias ha sido posible gracias a la financiación de la Dirección General de Patrimonio Histórico de la Comunidad de Madrid, la cual también realizó las gestiones pertinentes con Adif y el Ministerio de Fomento, propietarios del solar donde se ubica el yacimiento. Los trabajos de excavación y laboratorio han contado con la colaboración de Raquel Alonso, José María Barco, Mónica Barona, Gonzalo Calle, Ángeles Carrasco, Felipe Cuartero, Alfonso Expósito, Nuria Fernández, Daniel Herrero, Cristina de Juana, Adara López, Esther Martínez, Raquel Martínez, Iciar Moreno, Irene Ortiz, Pablo Paniego, José Antonio Perálvarez, Alba Pérez, Mario Ramírez, Nazareth Rincón, Irene Rivera, Raquel Rojas, Francisco Sánchez, Borja Sánchez-Cervera, Yolanda Sánchez y Alba Santamaría. Elizabeth Diaz ha colaborado en la fotografía de la industria lítica. La participación de Manuel Alcaraz-Castaño se ha visto favorecida por la concesión de una ayuda pre-doctoral FPU-MEC (referencia AP2006-1121). La participación de Javier Baena se enmarca en el proyecto "Algo más que bifaces: hacia la definición técnica y tecnológica de los conjuntos líticos del Pleistoceno de la región de Madrid" (HAR2010-20151). • 


\section{BIBLIOGRAFÍA}

Alcaraz-Castaño, M. 2014: La transición del Paleolítico Medio al Superior en el contexto de la historia disciplinar del Paleolítico (1852-1980). Un análisis historiográfico integral. Tesis Doctoral inédita. Departamento de Historia y Filosofía. Universidad de Alcalá. Madrid.

Alcaraz-Castaño, M., Alcolea, J., Balbin, R. de, Garcia Valero, M. A., YraveDRA, J. y BAENA, J. 2013: "Los orígenes del Solutrense y la ocupación pleniglaciar del interior de la Peninsula Ibérica: implicaciones del nivel 3 de Peña Capón (valle del Sorbe, Guadalajara)". Trabajos de Prehistoria 70 (1): 28-53.

Aubry, T., Walter, B., Robin, E., Plisson, H. y Benhabdelhadi, M. 1998 "Le site solutréen de plein air des Maîtreaux (Bossay-sur-Claise, Indre-et-Loire): un faciès original de production lithique". Paléo 10: 163-184.

Ayuntamiento de MadRid, 1929: Plano parcelario de Madrid. Escala 1:2.000. Adjunto a la Memoria de Información sobre la ciudad. Gerencia de Urbanismo del Ayuntamiento de Madrid. Hojas 86, 87, 96, 97, 98, 106, 107, 108 y 117.

BAENA, J. (ed.) 1998: Tecnología Lítica Experimental. Introducción a la talla de utillaje prehistórico. BAR International Series 721. Archaeopress. Oxford.

BAENA, J. 2002: "El Paleolítico en Madrid durante el periodo 1916-1936". En J. Panera y S. Rubio (eds.): Bifaces y Elefantes. La investigación del Paleolítico Inferior en Madrid. Zona Arqueológica 1: 80-107.

Baena, J., Bárez, S., Pérez-González, A., Roca, M., Lázaro, A., Márouez, R., Rus, I., Manzano, C., Cuartero, F., Ortiz, I., Rodriguez, P., Pérez, T., González, I., Polo, J., Rubio, D., Alcaraz-Castaño, M. y Escobar, A 2011 "Searchers and miners: first signs of Flint exploitation in Madrid's región". En M. Capote, S. Consuegra, P. Díaz-del-Rio y X. Terradas (eds.): Proceedings of the 2nd International Conference of the UISPP Commission on Flint Mining in Pre- and Protohistoric Times (Madrid, 14-17 October 2009). BAR International Series 2260. Archaeopress. Oxford: 203-220.

BAENA, J. y CARRIÓN, E. 2002: "Los materiales solutrenses". En C. Blasco Bosqued (coord.): La Colección Bento del Museu d'Arqueologia de Catalunya. Una nueva mirada a la prehistoria de Madrid. Museu d'Arqueologia de Catalunya. Barcelona: 79-130.

Baena, J., Conde C., Carrión, E. y PÁstor Muñoz, J. 2000: "Paleolítico y Epipaleolítico". En La Arqueología madrileña en el final del siglo XX. Boletín de la Asociación de Amigos de la Arqueología 39-40: 81-104.

BANKS, W. E., ZILHÃo, J., D'ERRICO, F., KAgEYAMA, M., SIMA, A. y RonCHITELII, A. 2009: "Investigating links between ecology and bifacial tool types in Western Europe during the Last Glacial Maximum". Journal of Archaeological Science 36 (12): 2853-2867.

Callahan, E. (2000): The Basics of Biface Knapping in the Eastern Fluted Point Tradition: A Manual for Flintknappers and Lithic Analysts, $4^{\mathrm{a}}$ ed. Piltdown Productions. Lynchburg. (1a ed. 1979).

Calvo, J. P., SAN JosÉ, M. A. y Vegas, R. 1989: Cartografía geológica del Terciario y Memoria correspondiente a la Hoja a E. 1:50.000 de Madrid (559) del Mapa Geológico de España. Instituto Tecnológico GeoMinero de España. Madrid.

Conde, C., CarRIón, E. y BaEnA, J. 2000: "Los modelos de explotación de los recursos líticos durante el Pleistoceno de la región de Madrid". SPAL. Revista de Prehistoria y Arqueología de la Universidad de Sevilla 9. Homenaje al profesor Vallespi: 145-166.

ENAMORADO, J. 1984: "El "Esbaikiense": sus implicaciones en la definición de una facies del Musteriense en el valle del Manzanares". Trabajos de Prehistoria 41 (1): 293-304.

- 1989: "La Torrecilla y La Parra: análisis de la industria lítica de dos yacimientos de época paleolítica en el valle del Manzanares, Madrid". Boletín del Museo Arqueológico Nacional VII: 9-27.

FreEMAN, L. G. 1975: "Acheulian Sites and Stratigraphy in Iberia and the Maghreb". En K. W. Butzer y G. LI Isaac (eds.): After the Australopithecines. Mouton Pub. The Hague-Paris: 661-744.
FreUnd, G. 1952: Die Blattspitzen des Paläolithikums in Europa. QuartärBibliothek 1. Ludwing Röhrscheid Verlag. Bonn.

- 1954: "Les industries à pointes foliacées du Paléolithique en Europe central". Bulletin de la Société Préhistorique Française 51 (3-4): 183-191.

GoY, J. L., Pérez-González, A. y Zazo, C. 1989: "Cuaternario y geomorfologia". Mapa Geológico de España, E. 1:50.000, Hoja 559, Madrid, 2a serie. IGME. Madrid.

JORDA CERDÁ, F. 1955: El Solutrense en España y sus problemas. Diputación Provincial de Asturias. Servicio de Investigaciones Arqueológicas. Oviedo.

Martinez de Merlo, A. M. 1984: "El Paleolítico Superior en el valle del Manzanares. El yacimiento de El Sotillo". Boletín del Museo Arqueológico Nacional 11: 47-68.

Mcbrearty, S., Bishop, L., Plummer, T., Dewar, R. y Conard, N. 1998: "Tools Underfoot: Human Trampling as an Agent of Lithic Artifact Edge Modification". American Antiquity 63 (1): 108-129.

OberMAier, H. 1925: El Hombre Fósil (2a edición refundida y ampliada). Comisión de Investigaciones Paleontológicas y Prehistóricas, Memoria 9. Museo Nacional de Ciencias Naturales. Madrid.

Obermaier, H. y Pérez de barradas, J. 1924: "Las diferentes facies del Musteriense español y especialmente de los yacimientos madrileños". Revista de la Biblioteca, Archivo y Museo del Ayuntamiento de Madrid, Año1 (2): 143-177.

Obermaier, H. y Wernert, P. 1918: "Yacimiento Paleolítico de las Delicias". Memorias de la Real Sociedad Española de Historia Natural XI: 5-35.

- 1929: "Alt-Paläolithikum mit Blatt-Typen". Mitteilungen der Anthropologischen Gesellschaft in Wien LIX: 293-310.

Pelegrin, J. y Chauchat, C. 1993: "Tecnología y función de las puntas de Paijan: el aporte de la experimentación". Latin American Antiquity 4 (4): 367-382.

PéreZ de BARRADAS, J. 1923: "Las terrazas cuaternarias del valle del Manzanares". Ibérica XX (486): 42-44.

- 1926: Estudios sobre el terreno cuaternario del Valle del Manzanares (Madrid). Imprenta Municipal. Madrid.

- 1934a: "Influences africaines dans le Paléolithique de Madrid". Anuario de Prehistoria Madrileña II-III: 3-11.

- 1934b: "El Acheulense del valle del Manzanares (Madrid)". Anuario del Cuerpo Facultativo de Archiveros, Bibliotecarios y Arqueólogos 1: 1-18.

Pérez-Gonzálezz, A. 1994: "Depresión del Tajo". En M. Gutiérrez Elorza (ed.): Geomorfología de España. Rueda. Madrid: 389-436.

RoYo Gómez, J., MenÉndez Puget, L. y ABBAD, M. 1929: Memoria explicativa de la Hoja Geológica a E. 1:50.000 n. ${ }^{\circ}$ 559, Madrid. Instituto Geológico y Minero. Madrid.

Rus, I. 1987: "El Paleolítico". En 130 años de arqueología madrileña. Real Academia de Bellas Artes de San Fernando. Madrid: 20-43.

Santonja, M., Pérez-González, A., y Vega, L. G. 2000: "El yacimiento de la estación de las Delicias (Madrid). La investigación del Paleolítico en el Manzanares". SPAL, 9. Homenaje al profesor Vallespi: 525-555.

Santonja, M., Pérez-González, A., Vega, L. G. y Uribelarrea, D. 2011: "La evolución de las ideas sobre el paleolítico en Madrid". En M. Santonja (coord.): Actas de las quintas jornadas de Patrimonio Arqueológico en la Comunidad de Madrid. Comunidad de Madrid. Madrid: 27-60.

SANTONJA, M. y Querol, M. A. 1980: "Características de la ocupación humana en los suelos achelenses de la terraza de Áridos (Arganda, Madrid)". En M. Santonja, N. López-Martínez y A. Pérez-González (eds.): Ocupaciones Achelenses en el valle del Jarama. Diputación Provincial, Madrid: 321-336.

TAPIAS, F., López-ReCIO, M., Dorado, M., Villaverde, R. y Dones, V. en prensa: "Estudio geoarqueológico de los depósitos del antiguo arroyo Carcavón (Madrid)". Octavas Jornadas de Patrimonio Arqueológico en la Comunidad de Madrid, Alcalá de Henares, Noviembre 2011. 
Manuel Alcaraz-Castaño, Mario López-Recio, Marta Roca, Fernando Tapias, Inmaculada Rus, Javier Baena, Jorge Morín, Alfredo Pérez-González y Manuel Santonja

Tapias, F., López-Recio, M., Manzano, I., Alcaraz-Castaño, M., Morin, J., Sesé, C., Dapena, L., Alarcón, A., Yravedra, J. y Arteaga, C. 2012: "Geoarqueología y Paleontología de los depósitos del Pleistoceno Superior del antiguo arroyo Abroñigal (Cuenca del Manzanares, Madrid): el yacimiento del Puente de los Tres Ojos". Cuaternario y Geomorfología 26 (1-2): 105-132.

TARDIEU, A. 1820: Plano de Madrid y de sus cercanías [sic]. P. Didot, Paris.
Tiffagom, M. 2006: De la Pierre à I'Homme. Essai sur une paléoanthropologie solutrénne. ERAUL 113. Université de Liège. Liège.

VAUDOUR, J. 1979: La région de Madrid, altérations, sols et paléosols. Ophrys. Aix-en-Provence.

Vega Toscano, L. G. 2001: "Aplicación de la metodología de los programas de investigación al análisis historiográfico del Paleolítico". Complutum 12: 185-215. 